\title{
Wind Power Integration Control Technology for Sustainable, Stable and Smart Trend: A Review
}

\author{
Hui-Jia Yang and Zhen-Yu Zhao*
}

\author{
School of Economics and Management, North China Electric Power University, Beijing 102206, China
}

\begin{abstract}
The key to achieve sustainable development of wind power is integration absorptive, involving the generation, transmission, distribution, operation, scheduling plurality of electric production processes. The paper based on the analyses of the situation of wind power development and grid integration requirements for wind power, summarized wind power integration technologies' development, characteristics, applicability and trends from five aspects, grid mode, control technology, transmission technology, scheduling, and forecasting techniques. And friendly integration, intelligent control, reliable transmission, and accurate prediction would be the major trends of wind power integration, these five aspects interactive and mutually reinforcing would realize common development both grid and wind power, both economic and ecological.
\end{abstract}

Keywords: Wind power, grid integration, grid mode, control technology, transmission technology, scheduling, forecasting techniques.

\section{INTRODUCTION}

During the last decade, the installed capacity of wind power generation has been increased tremendously all over the world. Wind power, which is the fastest-growing source of electric power generation, is proved to be a potential source for generation of electricity with minimal environmental impact. According to WWEA Half-year Report 2014, the worldwide wind capacity reached $3366^{\prime} 327 \mathrm{MW}$ by the end of June 2014, out of which 17'613 MW were added in the first six months of 2014. This increase is a substantially higher than in the first half of 2013 and 2012, when 13,9GW and 16,4 GW were added respectively. With $36.9 \%$ of the global installed capacity, Asia is now the continent with the most wind energy installed. Meanwhile, China has been by far the largest single wind market. Global growth of installed capacity of wind power from 1997 to 2014 is shown in Figures 1-2 [1].

Rapid installation, increased turbine size, and largescale wind farms development in worldwide would have a significant influence on operation and control of emerging power system which is expanding in terms of interconnections, network capacity, load demand, and addition of new devices for improving the performance of the system. Increased penetration of wind power with intermittent nature into electricity grid, how to forecast, control and improve the instability gives new challenges to transmission system operators (TSO) in maintaining reliability and stability of electricity supply.

*Address correspondence to this author at the School of Economics and Management, North China Electric Power University, Beijing 102206, China; Tel: +86 10 61773150; E-mail: zhaozhenyuxm@263.net
Therefore, grid integration and controls of wind power is one of the prime concerns as wind power penetration level is increasing continuously.

\section{GRID INTEGRATION REQUIREMENTS FOR WIND POWER}

\subsection{Generators and Grid}

The counterpart of synchronous machines in wind farms are mainly fixed speed asynchronous generators, doubly-fed induction generators (DFIG) and synchronous generators with back to back converts. The first generation of commercial grid connected wind turbines in the 1980s was dominated by fixed speed concept, mainly using asynchronous induction generators, which supplemented with a capacitor bank for reactive power compensation. Through 1990s, the DFIG concept became the most successful variable speed concept with more than $45 \%$ market share in 2002 [2]. The stator of these machines is connected directly to the grid, whereas the three phase rotor windings are supplied through a voltage source converter. By varying the voltage magnitude and frequency, the active and reactive power generated can be controlled and thus, the optimal rotor speed can be adjusted for any wind speed.

\subsection{Grid Connection Requirements (GCR) for Wind Power}

In the past, GCR for wind turbines or wind forms was not necessary due to limited level of wind power penetration. IEEE Standard 1001'IEEE Guide for Interfacing Dispersed Storage and Generation Facilities with Electric Utility System' was the only guideline for the connection of generation facilities to the distribution 


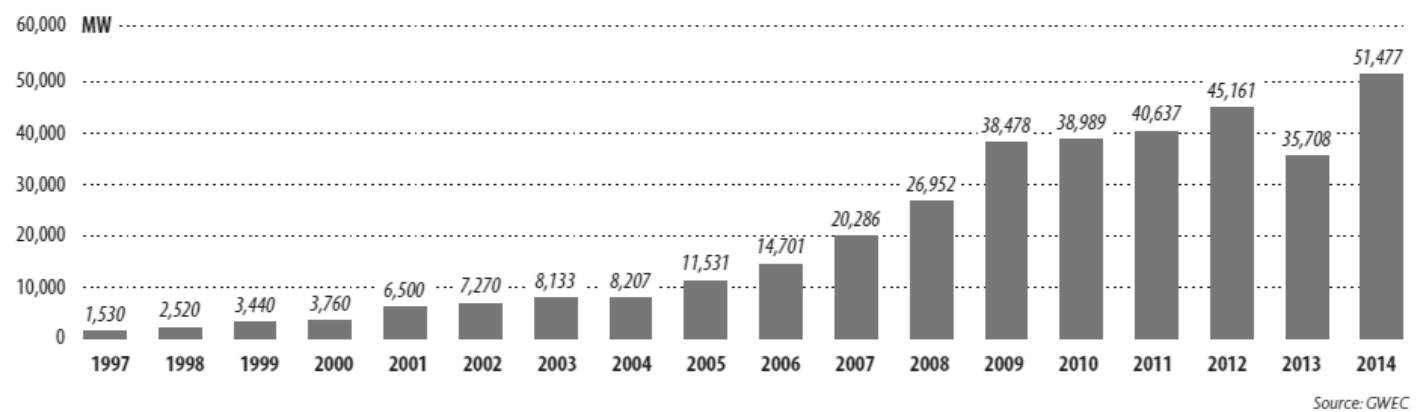

Figure 1: Global Annual Installed Wind Capacity 1997-2014 (Source: GWEC).

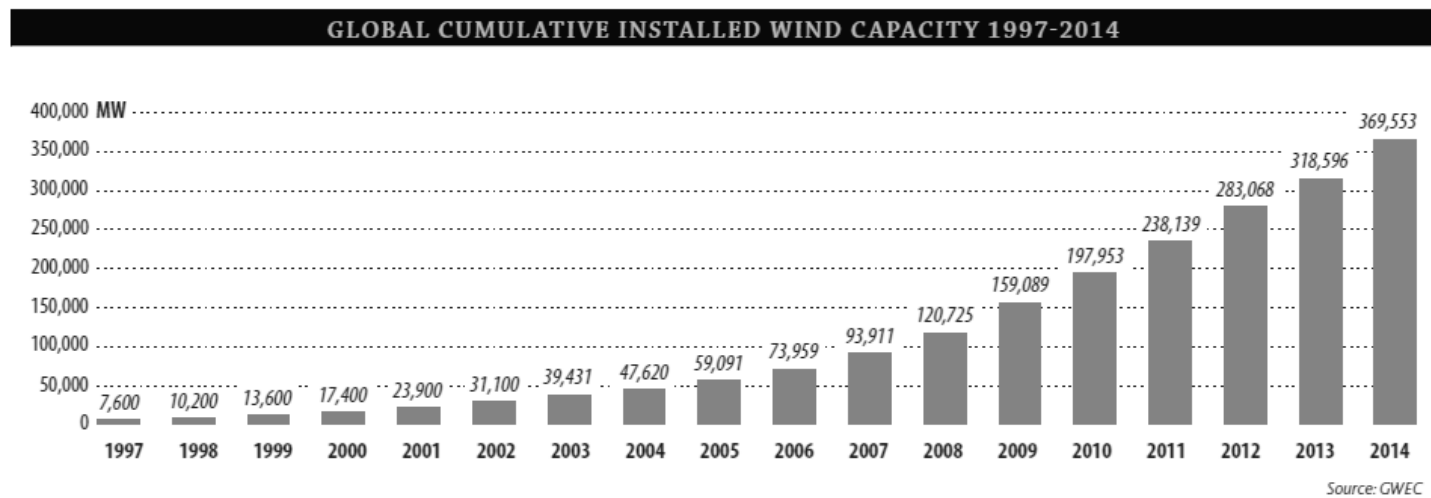

Figure 2: Global Cumulative Installed Wind Capacity 1997-2014 (Source: GWEC).

networks, which included the basic issues of power quality, equipment protection and safety. In 1998, the IEEE Working Group SCC21 P1547 started to work on a general recommendation for the interconnection of distributed generation, i.e., IEEE Standard for Interconnecting Distributed Resources with Electric Power System [3].

With the increasing wind power penetration and rapid development of wind turbine technology, not only was the increased size of the wind turbines, but also the growing size of the wind farms, which result in interconnection requests at the transmission level. Hence, new grid codes should be set up by specifying the relevant requirements for efficient, stable, and secure operation of wind power system, and there specifications have to be met in order to integrate wind power into modern electric grid. Table 1 presents the GCR issued by different TSO in the world [2].

The main focus in grid codes has been on the fault ride-though issue, where the TSO requires wind power generators to keep connected to the grid during and after a fault in the transmission system. Another important requirement to the wind power installations is on active and reactive power (voltage) control capability, to make installations able to support the control of grid frequency and grid voltage. Table 2 shows the grid stipulations in Germany, Denmark and the United States of active power control, reactive power control and low voltage through [4-8].

These enforced interconnection regulations guarantee the secure and economic operation of power system, reflecting the continuous development and improvement of integration technology of wind energy.

\section{WIND POWER INTEGRATION TECHNOLOGY}

\subsection{Integration Modes}

Grid-connected wind power system consists of wind energy resources, wind turbines, inverters, controllers and transformers, etc., can be divided into constant speed constant frequency (CSCF) and variable speed constant frequency (VSCF) two kinds of power generation, and the difference is the type of generator and circuit topology.

CSCF has small changes in the output frequency and the scope of blade speed variation, so called constant speed constant frequency. In actual operation, 
Table 1: Grid Codes from Different TSO

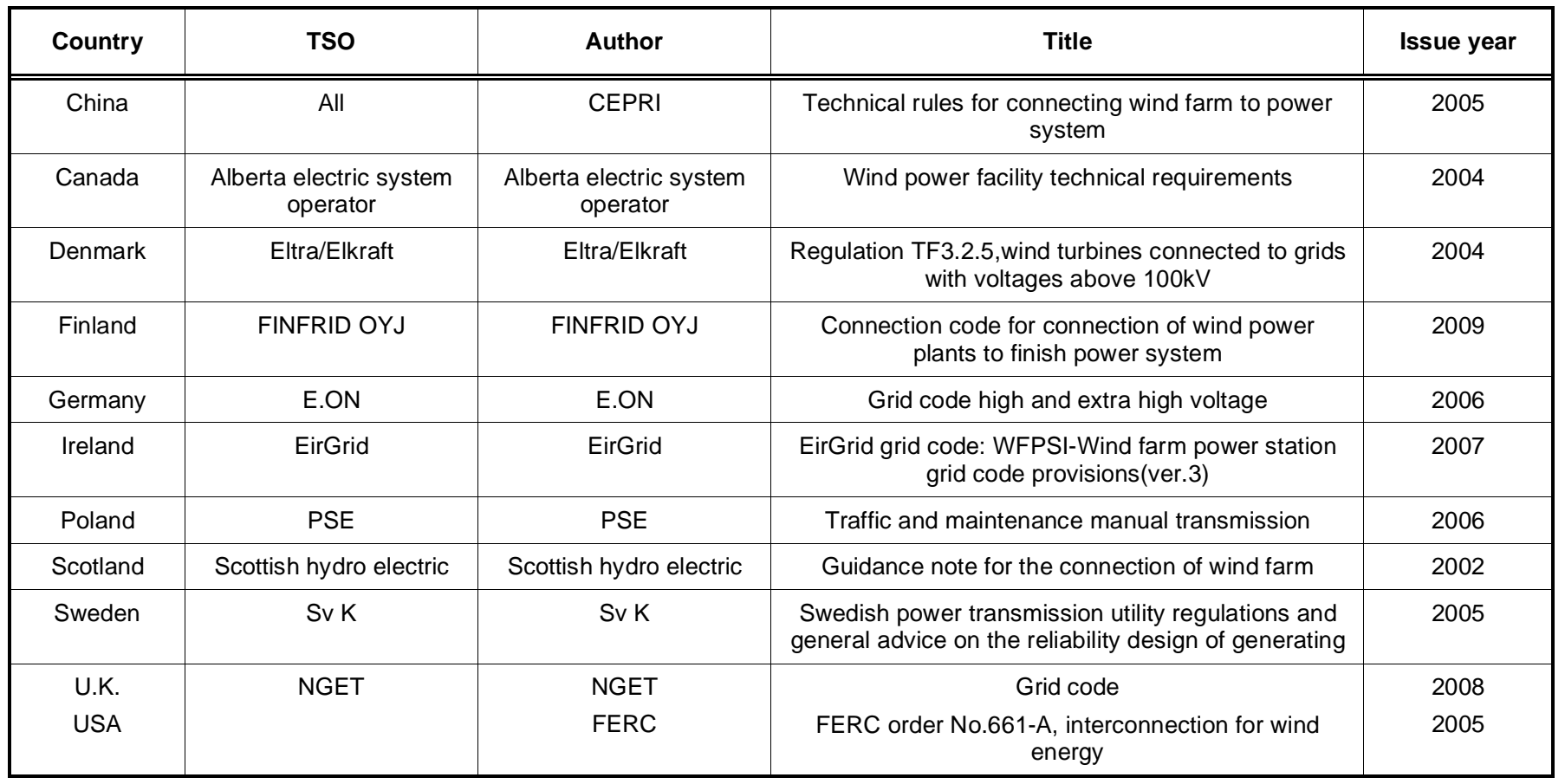

Table 2: Grid Stipulations in Different Country

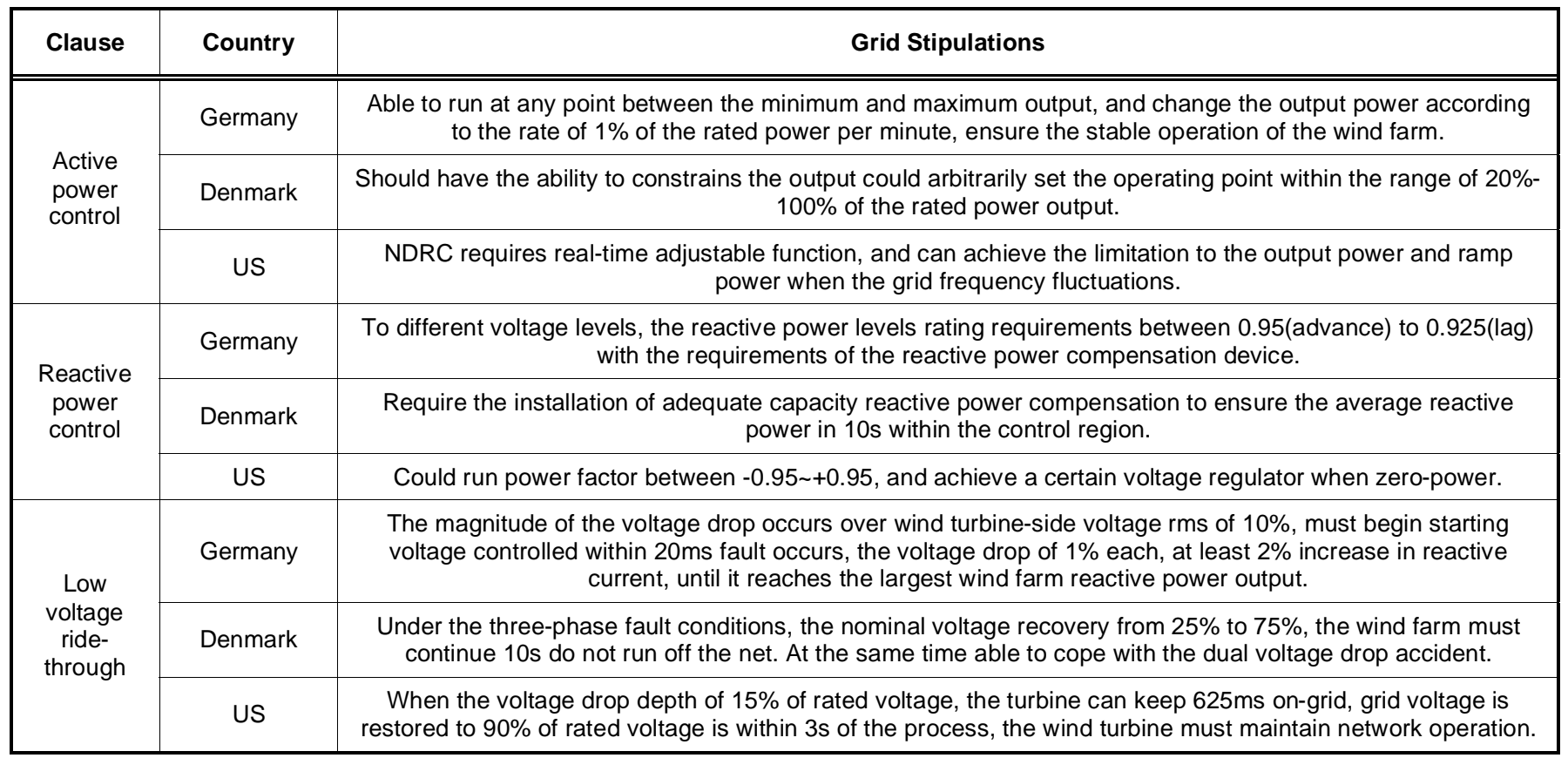

the wind turbine maintains the constant speed; which is determined by the number of poles of generator and gearbox. The system is equipped with synchronous and asynchronous generators. VSCF refers to the generator rotational speed changed with the wind speed, and the core is the inverter added between the generator and grid to obtain constant frequency electrical energy into the power system. This system usually equipped with the $A C$ excitation doubly fed asynchronous generator, synchronous generators. The advantages, disadvantages and applicable of integration modes of three mainly kinds of wind turbines shows in Table 3 [9-12]. 
Table 3: Analysis of Three Types Generators' Integration Modes

\begin{tabular}{|c|c|c|c|c|}
\hline Mode & Type & Advantage & Disadvantage & Applicable \\
\hline \multicolumn{5}{|c|}{ Asynchronous generator } \\
\hline $\begin{array}{l}\text { Quasi- } \\
\text { synchronizing } \\
\text { mode }\end{array}$ & CFCF & $\begin{array}{l}\text { small impulse current, tide } \\
\text { impact on grid voltage }\end{array}$ & $\begin{array}{l}\text { require precision governor and synchronization } \\
\text { equipment, high cost, complex adjustment }\end{array}$ & smaller grid capacity \\
\hline $\begin{array}{l}\text { Step-down } \\
\text { mode }\end{array}$ & CFCF & $\begin{array}{l}\text { small impulse current and } \\
\text { voltage drop }\end{array}$ & $\begin{array}{c}\text { add high-power resistance or reactor, poor } \\
\text { economy }\end{array}$ & $\begin{array}{l}\text { above } 100 \mathrm{Kw} \\
\text { capacity units }\end{array}$ \\
\hline $\begin{array}{l}\text { Captured quasi- } \\
\text { synchronous }\end{array}$ & CFCF & accurate, fast and reliable & complex control & $\begin{array}{l}\text { quasi-synchronous } \\
\text { integration }\end{array}$ \\
\hline Thyristor-SOFT & CFCF & smooth transition, reliability & $\begin{array}{c}\text { demanding device, complex control loop, high } \\
\text { cost }\end{array}$ & $\begin{array}{l}\text { Medium and large } \\
\text { turbines }\end{array}$ \\
\hline No-load mode & VSCF & $\begin{array}{l}\text { less equipment, simple, no } \\
\text { impulse current and } \\
\text { deterioration }\end{array}$ & $\begin{array}{l}\text { accurate control of speed regulating capability } \\
\text { etc., control performance deterioration }\end{array}$ & $\begin{array}{l}\text { large wind farms, } \\
\text { supplied directly to } \\
\text { the grid }\end{array}$ \\
\hline Load mode & VSCF & $\begin{array}{l}\text { no shock; reduce velocity } \\
\text { modulation capacity; reliability }\end{array}$ & $\begin{array}{l}\text { complex control, need voltage compensation } \\
\text { and resistive load }\end{array}$ & \\
\hline $\begin{array}{l}\text { Isolated- island } \\
\text { mode }\end{array}$ & VSCF & $\begin{array}{c}\text { format energy loops, before } \\
\text { integration, reduce the energy } \\
\text { loss }\end{array}$ & complex, need pre-charging, high cost & \\
\hline Electrodynamics & VSCF & simple & complicated, slow, energy loss & \\
\hline \multicolumn{5}{|c|}{ Synchronous generator } \\
\hline $\begin{array}{c}\text { Frequency } \\
\text { converter mode }\end{array}$ & VSCF & $\begin{array}{l}\text { no impulse current and lost } \\
\text { synchronization, deliver more } \\
\text { power under optimal efficiency, }\end{array}$ & $\begin{array}{l}\text { complicated control, high cost, exist a high- } \\
\text { frequency current flows to grid }\end{array}$ & \\
\hline
\end{tabular}

Due to the instability of wind speed, the output power and current shocks may cause a series of grid problems such as voltage fluctuations, steady-state changes. Therefore, investigating and analyzing the reasonable integration mode has become an essential link, and been guiding significance to analysis the impact on grid power quality.

VSCF has matured gradually in recent years and load integration mode widely used in actual unit. Compared to the CSCF system, it can buffer speed changes, reduce the output power fluctuation and mechanical stress, have control of active and reactive power respectively; reduce the mutual influence [12]; can capture the maximum wind energy effectively, work at maximum efficiency higher than $10 \%-15 \%$ of CSCF, CSCF system will be gradually replaced [13].

\subsection{Control Technique}

As the hub of the wind power system, control technology is the foundation to ensure the entire unit and grid's normal operation, safety and efficiency.

\subsubsection{Grid Control}

In the field of increasing the wind power admission capacity of grid, mainly process from security control, active control and reactive voltage control three aspect. As active power control, could summarized as 2 constraints (sent out and peak regulation), 3 control 


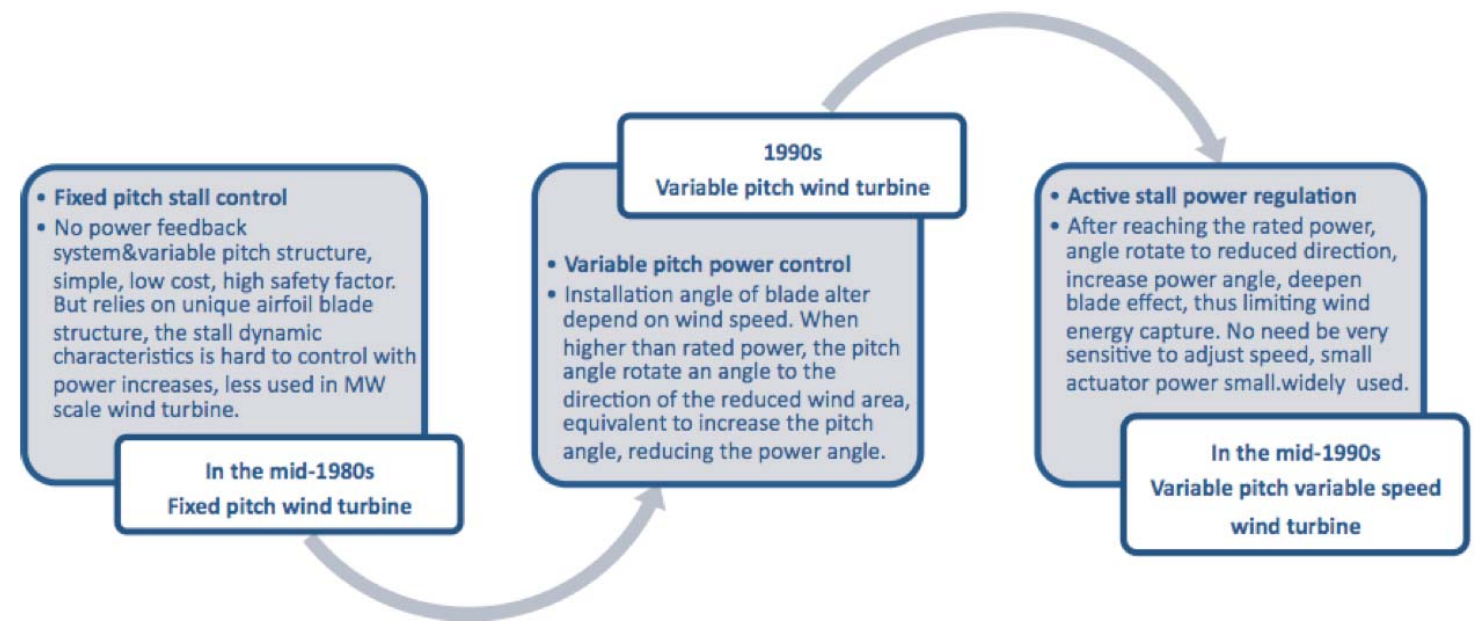

Figure 3: Power Control Corresponding to Representative Wind Turbine in Different Periods.

level (advanced, normal and emergency), 2 kinds of control modes (maximum output control mode and output tracking mode) [14].

\subsubsection{Wind Farm Control}

Wind turbines are complex and multivariate nonlinear systems with characteristics of uncertainty and multi-interference. The basic goal of wind farm generation control system is divided into four levels: reliable operate, maximizes energy, provide good power quality and prolong the life of the unit, besides eight major functional requirements [15].

\section{(1) Wind Turbines Power Control}

Power control is the essence of the pitch control. Figure 3 summarizes simple introduction of the power control technology in different periods corresponding to the representative wind turbine [16-17].

Wind turbine control technology develop from fixed pitch constant speed to variable pitch variable speed, the fundamental difference is that variable speed wind turbine regard the wind speed as input variables of control system, to achieve the regulation of the speed and power and reach the purpose of providing high efficiency and high quality electricity to grid.

\section{(2) Wind Turbine Unit Control System}

In traditional control technology, the linear control theory not meets the no-designed conditions of the nonlinear wind turbine. Subsequently, the development of nonlinear control theory transfers the nonlinear system into a linear system globally. With the development of modern control technology, the modern control methods include optimal control, robust control, sliding mode control, nonlinear adaptive control and intelligent control [18].

Intelligent control technologies full use of its nonlinear, variable structure, self-seeking superior capabilities to overcome the varying and nonlinear factors parameters of the system. Representative is the wind turbine intelligent control system based on fuzzy logic and neural networks.

Fuzzy logic control is not dependent on the accurate mathematical model of controlled object, nonlinear factors affecting overcome, and the adjusted object parameter has strong robustness, suitable for wind turbine unit control. Reference [19] described the fuzzy controller based on power deviation and adjusted inverter modulation point in PWM, to achieve maximum power operation under the rated wind speed. Reference [20] put forward fuzzy control on the basis of wind speed estimated to capture the maximum wind energy and improved system stability. Reference [21] used genetic algorithm' simple and efficient optimization characteristics optimize the structure and parameters of fuzzy controller.

The neural network has the nonlinear mapping capacity to approximate any arbitrary nonlinear model. Reference [22] used dual-mode control architecture for variable pitch wind power generation system with inner fuzzy controller and outer neural network controller, to achieve maximum wind replenishment and reduce the mechanical loads.

\subsubsection{Actual Cases}

Gansu Electric Power Company and China State Grid Electric Power Research Institute developed the 
active functions of a large cluster of wind power intelligent control system jointly in 2010. The system has been put into operation in March 2010, has currently run in good condition, improved the power output of wind farms, and ensured the safety of the power grid stable operation [23].

GE's Wind CONTROL TM control management system [24] through controlling the pitch angle adjustable active that can effectively regulate voltage and reactive power of wind farms or more distant locations. GE's Wind RIDETHRU TM by changing the control and protection functions of inverter, that make wind turbines have the capacity of maintain network without tripping (LVRT) when grid malfunction and voltage drops; even integration outlets voltage drop to zero (ZVRT). Practice has proved that the control system can significantly enhance the stability of the system significantly enhanced system stability.

\subsection{Transmission Technology}

With the expansion of the wind farm scale, rising voltage level and the proportion in grid, the impact scope of wind power's prominent feature of randomness and volatility has expanded from local to entire. Therefore, long-distance transmission technology of large-scale wind power has become the common problems in the face of the efficient development and utilization of wind power. To reduce the power loss of long-distance transmission of large wind power, high-voltage power transmission technologies are used in long-distance transmission network, as summarized in Figure 4.

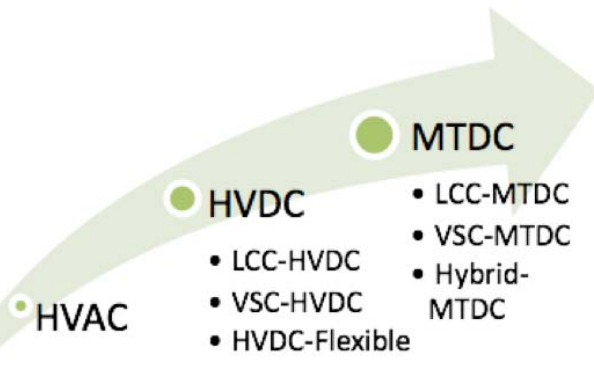

Figure 4: High-voltage Power Transmission Technologies in Wind Power Integration.

\section{(1) HVAC}

There are some technical bottlenecks of HVAC [25]: the prerequisite is strictly synchronized frequency of wind farms and the connected AC system; high capacitance effects lead to voltage waveform distortion is one of main factors causing off-grid; in the case of failure in AC system, the fault will be spread between wind farm and grid, required to install reactive power compensation device at wind farm side to improve fault ride-through capability of wind farms, which would increase overall investment; transport affected by distance, would form a huge reactive power, reduce active power transmission capacity, increase the power loss, over-voltage cable segment generated. HVAV is more suitable for small wind farm close to the grid, and cost-effective way for small interconnected offshore wind farms and AC grid [26].

\section{(2) HVDC}

HVDC could isolate AC grid fault propagation, not limited by cable charging current with high Electricity transmission efficiency, less loss, low voltage drop, no capacitive charging current, no transfer distance limitations; power loss is smaller than the equivalent AC cable project; no resonance between DC cables and other AC communications devices; have the ability to provide fast active and reactive power control [2728]. These features make the HVDC better meet the long-distance wind farm grid.

\section{$L C C-H V D C$}

Between 1970 and 1980, semiconductor technology has been rapid developed, the application of high power thyristor, directly contributed to the development of HVDC.

LCC-HVDC technique is mainly used for high pressure, high-power (generally more than 1000MW) inter-regional long-distance power transmission. Shanghai-Xiangjiaba 1800kV HVDC transmission project [29] is the highest voltage level built, longest transport distances and the largest capacity HVDC transmission project of the world, rated transport power capacity of $6400 \mathrm{MW}$.

LCC-HVDC connected to grid through converter transformer, could not control the active and reactive power independently, need to add a capacitor or adjust cameras for reactive power compensation. Meanwhile susceptible AC grid disturbances, and requires access to the AC grid system must be active and have sufficient capacity, otherwise easily lead to commutation failure, or even the entire HVDC system outage.

A large number of reactive power compensation equipment, $A C$ filter, switching stations and the DC 
smoothing reactor device requires a large space, which will require huge offshore converter station platform, increasing the complexity of the construction in extreme environments, therefore LCC-HVDC not suitable for offshore wind farm transmission grid. So far LCC-HVDC converter station projects are built on land [30].

\section{VSC-HVDC}

The concept of HVDC based on the voltage source converter first proposed in 1990 by Ooi B T from McGill University in Canada [31]. CIGRE and IEEE officially define as voltage source converter based high voltage direct current transmission, VSC-HVDC.

VSC-HVDC active and reactive power can be quick controlled independently no reactive power compensation; can supply power to the passive network and black start; easy to achieve power reversal, increase AC power transmission capacity and the angle of attack stability; Easy constitute multiport flow system; flexible and convenient construction and light weight design; VSC can play a static var compensator (STATCOM) role in providing for the exchange of dynamic reactive power grid. Especially VSC-HVDC uses turn-off devices, without the help of external voltage source, therefore application in offshore wind power, no external commutation equipment [32-33]. But this method has large system loss, small capacity, could not effective control on the DC side of the fault current [34].

Except the above characteristics, compare to LCCHVDC, VSC-HVDC has a compact, modular design, easy to move, installation, commissioning and maintenance, easy to expand and achieve MTDC, etc. So it's advantageous when connecting offshore wind farms, and the electricity transmission not limited by distance, therefore VSC-HVDC is only choice for large remote offshore wind farm integration [35-36]. Table 4 shows the VSC-HVDC projects used in wind power integration [26].

Shanghai Nanhui plant is consisted of 11 sets of $1.5 \mathrm{MW}$ wind turbines, $16.5 \mathrm{MW}$ total installed capacity. The VSC-HVDC has HVDC and STATCOM two operation modes, the maximum capacity of active transport system is $18 \mathrm{MW}, 16 \mathrm{MW}$ active output, largest compensate 9Mvar reactive to the grid the at the same time, avoiding investment in wind farm reactive power compensation device, fully meet the demand of reactive power for Nanhui wind farm running [37].

\section{HVDC- Flexible [31]}

Based on voltage source converter (VSC) and pulse width modulation (PWM), flexible HVDC technology can independently rapidly control the transmission of active and reactive power, which greatly enhances the flexibility of power transmission. Under the trend of large-scale wind farms and large-scale development, how to achieve high efficiency and high reliability of wind farm integration, HVDC-flexible transmission system still needs research.

The world's first used on-off devices with controlled voltage source converter HVDC project is Hellsigion experimental project and put into operation in Sweden in March 1997 [38], which inverter switching devices using Insulated Gate Bipolar Transistor (IGBT), and showed good power stability and transient performance. Sign of the times of HVDC into flexible HVDC era. Table $\mathbf{5}$ summarized HVDC-flexible Project has been put into operation [39].

Compared with the traditional HVDC, HVDC-flexible apply to the passive network power, to achieve active and reactive power control and independent and trend reversal; weaken the harmonics generated during IGBT switch to reduce the reactive power demand; Can

Table 4: VSC-HVDC Projects Used in Wind Power Integration

\begin{tabular}{|c|c|c|c|c|}
\hline Country & Project & Commissioning time & Capacity (MW) & Voltage (kV) \\
\hline \hline Sweden & Gotland & 1999.11 & 50 & \pm .2 \\
\hline Denmark & Tjaereborg & 2008.8 & 400 & \pm 7.2 \\
\hline Germany & Nord E. ON 1 & 2009.9 & 18 & \pm 150 \\
\hline China & Shanghai Nanhui & 2010 & 400 & \pm 00 \\
\hline Germany & BorWin1 & 2012 & 864 & 320 \\
\hline Germany & DolWin1 & 2013 & 2014 & \pm 320 \\
\hline Germany & SylWin1 & & 860 \\
\hline
\end{tabular}


Table 5: HVDC-Flexible Project Has Been Put into Operation

\begin{tabular}{|c|c|c|c|c|}
\hline Country & Project & Commissioning time & Capacity (MW/Mvar) & Voltage (kV) \\
\hline \hline Sweden & Heallsjion & 1997.3 & $3 / 3$ & \pm 10 \\
\hline Australia & Directlink & 1999.12 & $36 / \pm 36$ & \pm 80 \\
\hline US-Mexico & Eagle Pass BTB & 2000.9 & $330 / \pm 75$ & \pm 15.9 \\
\hline US & Cross Sound Cable & 2002.8 & $225 /+40--140$ & \pm 150 \\
\hline Australia & Murray Link & 2002.8 & $300 / 10$ & 145 \\
\hline Norway & Valhall & 2010.5 & 400 & \pm 200 \\
\hline US & Trans Bay Cable & 2010 & & 155 \\
\hline
\end{tabular}

stabilize the line voltage as STATCOM; each VSC individually controlled without communication [40-41]. Reference [42] used simulation software PSCAD / EMTDC analysis pre-feasibility study of Denmark Laeso S offshore wind farm's HVDC flexible systems, reproduces the wind farms under two different $A C$ and DC grid approach, the degree of grid voltage fault interference wind turbines and grid. Table 6 cites three topology of wind power HVDC-Flexible transmission [43].

Table 6: Three Topology of Wind Power HVDC-Flexible Transmission

\begin{tabular}{|c|c|}
\hline Type & Applicability \\
\hline \hline AC bus & $\begin{array}{c}\text { wind turbine which already or newly built coupled to a } \\
\text { particular power level, the fan capacity should not be } \\
\text { too large }\end{array}$ \\
\hline $\begin{array}{c}\text { Packet } \\
\text { type }\end{array}$ & $\begin{array}{c}\text { more open wind farms, different places with larger } \\
\text { disparity wind energy }\end{array}$ \\
\hline $\begin{array}{c}\text { DC bus } \\
\text { type }\end{array}$ & $\begin{array}{r}\text { high capacity requirements VSC transmission section, } \\
\text { use for wind farm expansion }\end{array}$ \\
\hline
\end{tabular}

\section{(3) MTDC}

MTDC (Multi-terminal HVDC) is meant to include two or more converter HVDC network. Compared to point transmission lines, this electricity transmission take full advantage of transmission path could achieve, and low cost [44]. Run flexible, accurate power exchange through multi-terminal DC system, once one end fails, can removal from the DC network without affecting the normal operation of the other end [45]. Currently, Corsica-Sardinia-Italy three-terminal transmission project, as well as Quebec-New England 5-terminal transmission project put into operation.

Compared with the two ends of HVDC, MTDC system in the following applications [46] to better reflect its economic and operational flexibility: transporting large amounts of electricity from the energy base to several distant load centers; the middle branch of the DC line access to power and the load; a few isolated AC system with DC line to achieve asynchronous networking.

Depending on the type of inverter, MTDC system can be divided into three types: Line-Commutated converter-MTDC; voltage source converter-MTDC; containing LCC and VSC converters of MTDC system (Hybrid-MTDC).

MTDC system architecture can be divided into two categories [47], one for each converter station is via DC lines is connected in parallel, and the other is a converter station via the DC line connected in series. Compared with the series program, parallel program flexible control, can provide more flexibility for future expansion.

In summary, collate the advantages and applicability of various types of transmission technology in Table 7.

As can be seen, with generation capacity of renewable energy increased and spatial distance decentralized, long-distance, high-capacity HVDC flexible and multi-terminal DC system has been well developed. It solve the puzzle of multi-supply, multiplacement and increase reliability and stability of wind power integration.

\subsection{Scheduling Technology}

Wind power optimal scheduling is to meet the system safe and stable operation under power constraints, according to the results of wind power forecasting space reserved for wind power to run, the implementation does not abandon the wind, is the key to achieve wind power integration consumption. Wind farm output power can be seen as a negative load. 
Table 7: Advantages and Applicability of Different Types Transmission Technology

\begin{tabular}{|c|c|c|}
\hline Type & Advantages & Applicability \\
\hline HAVC & strictly synchronized frequency & $\begin{array}{c}\text { small wind farm and small offshore wind farm between } A C \\
\text { grid }\end{array}$ \\
\hline LCC-HVDC & low power loss & high-power inter-regional transmission \\
\hline VSC-HVDC & $\begin{array}{l}\text { control active and reactive power independently, } \\
\text { provide rated short circuit current }\end{array}$ & offshore wind farm \\
\hline HVDC-Flexible & $\begin{array}{l}\text { no reactive power compensation and } \\
\text { commutation failures, high angle stability }\end{array}$ & $\begin{array}{c}\text { new energy integration, power supply to island and weak } \\
\text { grids }\end{array}$ \\
\hline MTDC & flexible, accurate exchange & large amounts of power transmission with branches \\
\hline
\end{tabular}

After integration, the available power peaking capacity for balancing minus load fluctuations spare capacity, the remaining capacity can be used for peaking. When the grid peaking capacity can used for of wind power is limited, cannot fully balanced output power fluctuations in the wind farm, will limit the wind power inject to grid.

\section{(1) Static Economic Dispatch}

The goal is to meet the load demand and operational constraints under the premise that the cost of electricity for digestion. Optimization mathematical model expression as:

$\min F=\sum_{n=1}^{N} f_{n}\left(\mathrm{P}_{n}\right)$

s.t. $\left\{\begin{array}{l}\sum_{n=1}^{N} P_{n}-P_{D}=0 \\ P_{n}^{\min } \leq P_{n} \leq P_{n}^{\max }\end{array}\right.$

$N$-the number of units;

$n$-the generator group number;

F-the system cost;

$P^{D_{\text {-system load; }}}$

$f_{n}\left(\mathrm{P}_{n}\right)$-characteristic function of coal consumption;

$P_{n}^{\min } P_{n}^{\max }$ - lower and upper generation unit power.

Static economic dispatch only research active allocation between the given time section of generator sets. Therefore, dynamic economic dispatch has developed, it consider the interaction between the different time sections, based on the load forecasting curves extend the study to a time period of active allocation problem. By arranging a certain period each generator output plan, so that optimal economic system under load and meet security requirements of the premise.

\section{(2) Dynamic Economic Dispatch}

Dynamic economic dispatch optimization model is better than the static economic dispatch, reflects the actual operational requirements, and has played a major role in power system operation and control.

Against economic dispatch of wind farms technology should consider are [48]:

$\ominus \quad$ Wind energy is renewable and clean nature, in addition to the necessary investment and maintenance costs, wind power network will bring more long-term environmental and economic benefits, in the scheduling model, the objective function can be considered fuel conventional units costs.

$\ominus \quad$ Wind power with fluctuations and intermittent features proposed the corresponding requirements for frequency response and climbing net run rate of the other units in scheduling.

$\circledast \quad$ The presence of wind power prediction error increases the uncertainty of the system after wind power integration, need more additional spinning reserve capacity. Spare capacity depends on prediction accuracy, higher prediction accuracy, less spinning reserve capacity needed, the smaller corresponding costs.

How to take advantage of wind power prediction information, rational allocation system spinning reserve capacity in order to ensure system reliability and economy of operation, is also a key in wind power system dynamic economic dispatch. 
Without considering wind farm operating costs as the premise, goal of economic dispatch of power systems with wind farms is to make the cost of conventional turbines in power generation systems minimum [49]. The costs of system dynamic economic dispatch considered valve point effect of conventional units of generation expressed as:

$\min F=\sum_{t=1}^{T} \sum_{n=1}^{N}\left\{\begin{array}{l}a_{n}+b_{n} P_{n, t}+c_{n} P_{n, t}^{2} \\ +\left|e_{n} \sin \left[f_{n}\left(P_{n}^{\min }-P_{n, t}\right)\right]\right|\end{array}\right\}$

Optimization constraints shown in Table 8:

Table 8: Optimization Constraints

\begin{tabular}{|c|c|}
\hline Constraints & Expression \\
\hline \hline Power balance constraints & $\sum_{n=1}^{N} P_{n, t}+\sum_{k=1}^{N_{w}} P_{k, t}-P_{D t}=0$ \\
\hline $\begin{array}{c}\text { Conventional generator output power } \\
\text { upper and lower bound }\end{array}$ & $P_{n}^{\min } \leq P_{n, t} \leq P_{n}^{\max }$ \\
\hline $\begin{array}{c}\text { Conventional generators up and } \\
\text { down climbing constraint }\end{array}$ & $D_{R n} \leq P_{n, t}-P_{n, t-1} \leq U_{R n}$ \\
\hline
\end{tabular}

Positive, negative spinning reserve constraint [50].

Economic dispatch of system with wind farm is typical of high-dimensional, multi-constrained, nonlinear mathematical programming problem, and the objective function considering valve point effect of generator so that the optimization problem becomes non-convex. Traditional methods to solving optimization problems, general require objective function is rectifiable derivative, easy lead to local optimum and other issues. In recent years, genetic algorithms and particle swarm algorithms, artificial intelligence algorithms have been used in large-scale, high dimension, nonlinear, non-convex, various types and multi-constrained of power system operation and control of optimization problems.

\section{(3) Scheduling Model Considered Environmental Impact}

With the development of wind power technology, the attendant environmental problems receive more and more attention. The main problem comes from the process of primary energy is converted to electrical energy. It is necessary to consider the impact of the environmental benefits of wind power on scheduling. Kennedy et al. [51] proposed a new method and evaluation model for evaluating environmental benefits from large-scale wind power integration. Yuan Tiejiang et al. [52] took full account of each turbine and environmental cost of energy under the power market mechanism, established the environmental economic power dispatch optimization model of electricity system with wind power aimed to electricity market. Simulation results illustrate the consideration of environmental factors in the cost of wind power can make alternate model is more reasonable, economy and reliability.

When the wind power cannot be accurately predicted, the grid must have more conservative solutions for wind power leaving enough spare capacity to balance fluctuations. Therefore, joint scheduling technology strategy of wind turbine and conventional thermal power proposed. For example, some studies proposed strategy to arrange spinning reserve capacity to respond to random fluctuations of wind farm power generation, in order to maintain the system power balance and stability [53-54], power system dynamic economy a scheduling strategy with wind farms [5556], AESO Canada has developed a scheduling decision support tools Dispatch Decision Support Tool (DDST) model, it integrate the real-time system information and data related to supply and demand balance together as data platform. Based on this information, data and algorithms, DDST can help system operators evaluate the ability to regulate the electricity market, supply shortages and excess risk, provide basis decisions to operating personnel [57].

In summary, the new energy grid scheduling strategies and models against the development of system generation dispatching plan with the wind power, Emphasis on wind power prediction technology, while auxiliary scheduling strategy with conventional thermal power units fitted. However, when large-scale wind power to attract, need to adopt a more flexible, efficient power generation scheduling strategy, to enhance the grid to absorb wind power, the ability to take advantage of wind energy, so it is necessary to study the generation scheduling model with wind power systems.

\subsection{Forecasting Techniques}

Large-scale wind power integration makes the electricity production and scheduling institutions need to master wind power output, in order to in order to formulate reasonable dispatch plan. The wind power prediction is important technical support to ensure that the power grid could balance wind power fluctuations, reduce spare capacity, and achieve. 
Table 9: Wind Farm Output Prediction Methods

\begin{tabular}{|c|c|c|}
\hline Basis & Method & Feature or applicable \\
\hline \multirow{4}{*}{$\begin{array}{l}\text { Time } \\
\text { dimension }\end{array}$} & Long Term (>1year) & For wind resource or pre-construction feasibility assessment \\
\hline & Medium Term (weeks) & For the wind farm maintenance arrangements \\
\hline & Short Term (48-72h) & For scheduling \\
\hline & Very Short Term (min) & For wind turbine control and power quality studies \\
\hline \multirow{3}{*}{$\begin{array}{l}\text { Forecasting } \\
\text { range }\end{array}$} & Single unit prediction & For wind turbine output control \\
\hline & Wind farm prediction & For wind farm management and communication \\
\hline & Wind area prediction & For wind power output correlation analysis \\
\hline \multirow{2}{*}{$\begin{array}{l}\text { Forecasting } \\
\text { model }\end{array}$} & Statistical model & $\begin{array}{l}\text { Constitute historical statistics based on the output power of the measured data; } \\
\text { According to principles of continuity and analogy, using linear or nonlinear prediction } \\
\text { method to predict the future value. }\end{array}$ \\
\hline & Physical model & $\begin{array}{l}\text { Calculate wind speed of wind turbine wheel height, according to NWP; no need lots of } \\
\text { historical data, practical good, need provide adequate weather conditions }\end{array}$ \\
\hline
\end{tabular}

Wind farm output prediction methods can be divided in different angles as Table $\mathbf{9 .}$

Because the wind is formed by the atmosphere flowing action, and therefore the wind speed is a typical random variable. Without considering the directionality of the wind, the wind speed is a function of its spatial position coordinates and time, i.e., $v=f(x, y, z, t)$. It describes a region wind spatial, temporal variation distribution characteristic, called Wind Field Model. Due to the randomness of the wind, the wind field topography and other factors, wind speed on each spatial location will various, almost impossible to establish an accurate wind field model, hence need for simplification. Predictive models commonly used: [58]

(1) Continuous prediction method [59]. It's the earliest and most simple prediction method based on the atmospheric system inertia principle, considered the future value equal to recent wind power measured value. Overall, the predicted results are lower accuracy and unstable.

(2) Grey prediction method [60]. Using gray model prediction model, select the historical month average or annual averages of wind speed, and then calculated the average of the future month.

(3) Kalman filtering method. The method regard wind speed as a state variable established statespace model, achieve the predict wind speed by Kalman filter algorithm. The application difficulty lies in the estimated statistical properties of noise.
(4) Random time sequence method. It mainly used large amounts of historical data to build predictive models. After data analysis, model identification, parameter estimation, model checking and other steps, determine a mathematical model to describe wind speed sequence, and derive the prediction model. The method most frequently used is cumulative autoregressive - moving average model [61]. Only need a single wind speed time series of wind farms to build predict model, and ultimately predict results with higher precision.

(5) Artificial Neural Network. ANN involved in a number of areas of biological, electronics, computers, etc., connected by a large number of simple processing elements in some large-scale topology structure, designed to mimic the human brain structure and function. This method has the parallel processing, distributed storage and fault tolerance features, but also has a self-learning, self-organizing and adaptive capacity, can achieve a variety of functions, is more suitable for short-term wind speed prediction.

(6) Fuzzy Logic method. This method use application fuzzy logic and forecasting personnel data form the fuzzy rule base. Then choose a linear model approximate to nonlinear dynamic wind speed. Under normal circumstances, due to weak learning capacity of fuzzy prediction method, has not yet formed a sound identification of fuzzy systems theory, therefore the effect of simple fuzzy method for predicting wind speed is often poor usually used with other methods. 
(7)

Spatial correlation method. This method first need to get multiple sets of wind speed data of the wind farm as well as several similar locations, then use the space correlation between wind speed of several locations to forecast wind speed. In order to obtain several sets of raw data needed for wind speed, need to set up several remote gun stations at wind farms surrounding areas. Obtained multi-point wind speed data through the real-time processing by the central computer, can predict wind speed utilized spatial correlation. Disadvantage of this method is nee to collect a large amount raw data, but the prediction process takes into account many factors, so the prediction accuracy is better. Currently, the method needs further improvement.

(8) Support vector machine approach. Similar to neural networks, support vector machines also have a strong learning ability and nonlinear mapping capability. The method by mapping the wind speed data to high-dimensional vector space, and then solving a quadratic programming problem, the eventual establishment of wind speed forecasting models. This method has been shown. This method proved to have good prediction accuracy and performance, is considered to be emerging intelligent algorithm may replace neural network, the learning process is additionally due to its lower complexity, computing faster, able to continue to expand the scope of application.

(9) Combination forecasting method. It weighted combination of several forecasting methods, the aim is to eliminate defect of single prediction methods, to improve the prediction accuracy of the target. This method has two main ideas: Preprocessing the wind speed data, such as decomposition, and then predicting multi components separately, finally combine the forecast results to achieve the whole forecasting process, is a one-step prediction of wind speed. Another is on the basis of already predicted wind speed, re-establishment of the model, previous step prediction value as a new training sample to achieve the whole forecasting process, is a multi-step prediction of wind speed. The former combination forecasting very broad application, the latter mainly use linear combination forecasting model to predict.
Bates and Granger proven combination of two or more unbiased prediction method is superior to single prediction [62]; Reference [63] establish a combination of artificial neural network model and spatial correlation analysis, without the need for detailed weather conditions and geographic data to achieve a good prediction; Reference [64] established a combination forecasting model based on artificial neural networks and time series; Reference [65] combine fuzzy theory and spatial correlation analysis; Liu Chun [66] use BP neural network, RBF neural network and SVM forecasting wind power, use weighted average method, covariance preferred combination forecasting method and time-varying weights of combination forecasting method to determine the weights. Studies have shown that the combination forecasting model can effectively reduce large errors prediction point, the prediction accuracy is greatly improved; Mohammad et al. [67] combined fuzzy logic and artificial neural networks, raise a new type of artificial intelligence methods for predicting wind speed, results indicate that a combination of wind speed forecasting model has better prediction performance.

Countries with developed wind power technology, has developed several short-term forecasting system for wind power prediction. Table 10 shows a typical forecasting system abroad [68].

\section{TRENDS OF WIND POWER INTEGRATION CONTROL TECHNOLOGIES}

The integration of wind power let the grid system need to make adjustment from grid mode, control technology and other aspects, combined with the corresponding transmission, scheduling technique to accommodate to large-scale wind power centralized access, long-distance transmission, wide range of consumption, achieve comprehensive economic and efficient use of wind energy, and safety, stability system operation after access a large-scale wind power.

Wind power integration will develop towards online, practical, visual; achieve online, real-time simulation analysis techniques combined with the early warning, detection; realize monitoring, analysis and evaluation of the full cycle of generation; increase wind power application level in transportation, heating, electricity and other industry parties [69]. Turbines need to continuously improve and optimize mechanical drive components and converter, improve operational stability and increase wind energy utilization efficiency, 
Table 10: Foreign Typical Wind Prediction System

\begin{tabular}{|c|c|c|c|}
\hline Lanberg & Lanberg & Physical methods & Denmark \\
\hline Prediktor & Denmark Riso & $\begin{array}{c}\text { Physical model } \\
\text { (HIRLA, WAsP, PARK) }\end{array}$ & $\begin{array}{c}\text { Denmark, Ireland, France, } \\
\text { Germany, USA }\end{array}$ \\
\hline Previento & Germany Oldenburg & Combination methods & Germany, Ireland \\
\hline eWind & USA Truewind & Combination methods & USA \\
\hline WPMS & Denmark & ANN based on NWP & Germany \\
\hline Sipreolico & Spain & Statistical methods & Spain \\
\hline Local Pre\&RegionPred & Spain M.Perez & Combination methods & Ireland, Spain \\
\hline Alea Wind & Spain & Statistical methods & Spain \\
\hline SOWIE & Germany & Physical methods & Germany, Sweden \\
\hline EPREV & Portugal & Statistical methods & Portugal \\
\hline Scriocco & Netherlands & Combination methods & Netherlands, Germany \\
\hline
\end{tabular}

reduce energy consumption and enhance the function of dynamic power, improve power quality, reduce the impact of the impact on the grid when the grid.

In terms of control technology, can be summarized as "hybrid drive mode" "load assessing control," "selftolerant control," "self-sustaining operation mechanism," the four development trends [70]. At the same time, the level of intelligence and reliability will continue to improve. Through advanced computer technology, communication technology and control theory, intelligently acquisition, analysis, processing the operation information, guarantee safety, efficiency of wind power generation. Full account of the volatility of wind; rising short-term, ultra-short-term power generation forecast accuracy; LVRT capability will significantly enhance the ability to upgrade withstand to system failures. Build a centralized control platform, in response to regulatory directives, complete with coordinate scheduling, emergency control external; coordinate and control of each wind farm and reactive power compensation equipment internal, realize active internal control online, adjust reactive power and voltage, optimization operate and local security policy [14].

In terms of transmission technology, HVDC and large-scale energy storage technology will be developed. With the increase capacity of renewable energy generation, more decentralized spatial distance, long-distance, high-capacity HVDC flexible and multiterminal DC system will be a good development, to solve the multi-supply, multi-placement electrical problems, improve reliability and stability of wind energy integration. At the same time, develop economic, efficient and environmentally friendly highcapacity energy storage technologies, smooth wind power output; reduce the negative impact of fluctuations in power output of renewable energy on the grid.

In terms of scheduling, dynamic economic dispatch and multi-energy complement will be more widely used. By increasing hydro/thermal power supply regulation, expanding wind/PV consumptive range, carry a wind farm/photovoltaic power plants power prediction and strengthen control of the wind farm/photovoltaic power plants and other measures to improve peaking capacity of the entire system, increase cross-transmission intensity and sent fire, water, wind, light and other power to the load center with large scale and relatively strong adjustment capacity.

Forecasting techniques, against power and wind speed forecast, combination forecasting method has a broad development space. After has clearly 
acknowledge the range of various prediction technique, strengthen error prediction and credibility analysis model's development and maturity, effectively reducing the prediction error from prediction system, hence the system can meet the requirements of the power system economic dispatch from the time scales and precision scales.

\section{CONCLUSION}

Wind power integration get into a rapid development period and has great potential in the future. The growth rate of wind turbine size and generator capacity has been accelerating, $5 \mathrm{MW}$ unit capacity of wind turbines has entered commercial operation phase; the construction of wind farms would expand from land to offshore; and national and regional policies are the important drivers for wind energy deployment. With the prospects of wind power from generator, wind farm and policies, the study of key integration technologies become deeper and more practical significances, but there still being insufficient and space to perfect.

Randomness and volatility of wind energy put forward higher requirements for integration, the related integration technologies has high correlation from generation, transmission, distribution some aspects. Full understanding and analysis of the techniques would help to achieve the improvement and innovation, form a coordinate and friendly integration situation of wind power, significantly improved power transmission quality, more intelligent control technology, enhance cross-regional multi-energy complement capabilities, promote rational scale development of wind energy, to achieve full use of renewable energy and efficient interconnection between wind energy power and grid.

\section{ACKNOWLEDGEMENT}

This work was funded by the Humanities and Social Sciences Planning Fund of the Ministry of Education of China (No.12YJAZH205), Beijing Philosophy and Social Science Planning Project (No.12JGB067), and the Natural Science Foundation of Hebei Province of China (No.G2012502065).

\section{REFERENCE}

[1] GWEC. Global Wind Statistics 2014. Report, Brussels, Belgium, February 2015.

[2] Muyeen SM. Wind energy conversion systems: technology and trends. London: Springer 2013.

[3] Ackemann T. Wind power in power system. Wiley, England, 2005; pp. 115-142.

http://dx.doi.org/10.1002/0470012684
E. ON Netz GmbH Bayreuth. Grid code of high and extra high voltage 2006.

[5] E.ON Netz GmbH Bayreuth. Requirements for offshore grid connections in the E.ON Netz network 2008.

[6] Youxing $S$, et al. Wind power development experience of Denmark and its reference to China. East China Electric Power 2008; 36: 153-7.

[7] American Wind Energy Association. American Wind Energy Association annual wind industry report. Washington, DC: AWEA, 2008

[8] Jianye $R$, et al. Comparison on technical regulations of China and other countries for grid-connection of wind farms. Power System Technology 2012; 08: 44-9.

[9] Jianlin L, Dongli Z, et al. Comparison and analysis on network synchronization modes of several kinds of variable speed constant frequency wind power generator. Electric Power Construction 2006; 27:8-11.

[10] Shoudao H, Yanzhao S, Keyuan H. Review on cutting-in strategies of wind power. $J$ of Electric lower Science and Technology 2008; 23 (2): 13-8.

[11] Tengfei L, Yuegang L, et al. Review of syn-chronization technology of wind power generation system. Electric Power 2009; 42(11): 61-5.

[12] Qiming C, Yiman C, et al. Research on review of gridconnected technology of wind power generation. East China Electric Power 2011; 02: 39-44

[13] Ke L. Research and design of shunt-connected wind power generation. Micromotor 2010; 02: 83-6.

[14] Yu D, Yonghua C, Xueming L, et al. Status qua and prospect on control technique for large-scale synchronization of wind power. Guangdong Electric Power 2011; 05: 24-28+38.

[15] Leithead W, et al. Role and objectives for control of wind turbines. IEEE Proc-C 1991; 138(2): 135-48.

[16] Xinfang $Z$, Daping $X$, et al. Overview of technological developments and relevant control problems of wind turbines. North China Electric Power 2005; 05: 42-5.

[17] Jingjing $Z$, Ping $Y$, et al. Study on control systems for winddriven power generation. Process Automation Instrumentation 2006; S1: 32-5.

[18] Dexing $\mathrm{H}$. Some questions in the developing of wind power. World Science-technology R\&D 2003; 04: 44-8.

[19] Hilloowala RM, Sharaf AM. A rule-based fuzzy logic controller for a PWM inverter in a standalone wind energy conversion scheme. IEEE Trans on Industry Applications 1996; 32: 57-65. http://dx.doi.org/10.1109/28.485813

[20] Perales M, Perez J, Barrero F, et al. Fuzzy logic control of a variable speed variable pitch wind turbine. The 25th Annual Conference of the IEEE 1999; pp. 614-618.

[21] Song W, Xingjia Y. Application of genetic algorithm in variable pitch wind power control system. New Energy 2000; 22: 48-51.

[22] Chedid R, Mard F, Basma M. Intelligent control of a class of wind energy conversion systems. IEEE Trans. on Energy Conversion 1999; 14(4): 1597-1604. http://dx.doi.org/10.1109/60.815111

[23] Xueming L, Zhou X, Zhenhuan C, et al. Exploitation of large clusters of wind power active intelligent control system. Automation of Electric Power Systems 2010; 34(17): 59-63.

[24] Clark K, Miller N. WindFREE ${ }^{\mathrm{TM}}$ reactive power control for wind turbine generators. Nordic wind power conference, Espoo, Finland 2006.

[25] Jianhu B, Songxu X, Dexu J. Analysis on the planning and operation problems of large-scale wind power development in China. Electric Power Technologic Economics 2009; 21(2): 7-11. 
[26] Xinmin F. Research on the control strategy of VSC- HVDC and VSC- MTDC systems for wind farm-grid connection. PhD Thesis, South China University of Technology, China, 2014.

[27] Van Eeckhout B, Van Hertem D, Reza M, et al. Economic comparison of VSC- HVDC and HVAC as transmission system for a $300 \mathrm{MW}$ offshore wind farm. European Transactions on Electrical Power 2010; 20(5): 661-71.

[28] Aishling R, Rick W. Comparison of VSC based HVDC and HVAC interconnections to a large offshore wind farm. IEEE Power Engineering Society General. San Francisco, CA, United States 2005; 1-8.

[29] Yiming $Y$, Yanming C. Operational test of xiangjiabashanghai $\pm 800 \mathrm{kV}$ UHVDC thyristor valve on the synthetic test circuit. High Voltage Engineering 2010; 36(1): 281-284.

[30] Wanjun Z. HVDC technology. Beijing: China Electric Power Press, 2004.

[31] Ooi BT, Wang X. Boost type PWM HVDC transmission system. IEEE Trans on Power Delivery 1991; 6(1): 1557-63. http://dx.doi.org/10.1109/61.97692

[32] Hairong C. Control and protection of VSO based HVDC system under AC system fault conditions. PhD Thesis, Zhejiang University, China, 2008.

[33] Negra NB, Todorovic J, Ackermann T. Loss evaluation of HVAC and HVDC transmission solutions for large offshore wind farms. Electric Power Systems Research 2006; 76: 91627.

http://dx.doi.org/10.1016/j.epsr.2005.11.004

[34] Wulue $P$, Zheng $X$, Jing Z, et al. Dissipation analysis of VSCHVDC converter. Proceedings of the CSEE 2008; 28(21): 714.

[35] Lin L, Ming Y, Fang Y, et al. German Offshore Wind Power Development: Analysis and Enlightenment. Energy Technology and Economics 2011; 23(8): 47-52.

[36] Kent HS, Peter C. DC feeder for connection of a wind farm. CIGRE, Kuala Lumpur, Malaysia 1999; 1-5.

[37] Yifan Z. Application of flexible HVDC transmission technology in grid-connected wind power. East China Electric Power 2011; 07: 1130-1133.

[38] Asplund G, Eriksson K, Svensson K. DC transmission based on voltage source converters. CIGRE SC14 Colloquium, South Africa, 1997; pp. 1-8.

[39] Cunjian T. Application and research of HVDC flexible in wind power. PhD Thesis, Nanchang University, China 2013.

[40] Jun W, Yigong Z, Mingxiao H. HVDC based on voltage source converter-a new generation of HVDC technique. Power System Technology 2003; 27(1): 47-51.

[41] Qian C. Operation and control of VSC based multi-terminal HVDC system. PhD Thesis, Southeast University, China 2004.

[42] Kent S, Dennis W, Regine B. AC cable versus DC cable transmission for offshore wind farms, a study case. Fourth International Workshop on Large-Scale Integration of Wind Power and Transmission Networks for Offshore Wind Farms; Denmark 2003.

[43] Perez M, Rodriguez J. Power distribution in hybrid multi-cell converter with nearest level modulation. Proc IEEE ISIE 2007.

[44] Balu NJ, et al. Multiterminal HVDC control for evaluating power transfer capability in combined AC-DC systems. International Conference on Large High Voltage Electric Systems; Paris, France 1986.

[45] Carroll DP, Ong CM. Coordinated power modulation in multiterminal HVDC systems. IEEE Trans on Power Apparatus and Systems 1981; PAS-100(3): 1351-1361. http://dx.doi.org/10.1109/TPAS.1981.316608
[46] Long WF, Reeve J, McNichol JR. Applihbucation aspects of multi-terminal DC power transmission. IEEE Transactions on Power Delivery 1990; 5(4): 2084-2098. http://dx.doi.org/10.1109/61.103704

[47] Xia C. Wind power integration using multi-terminal HVDC technology. PhD Thesis, Huazhong University of Science \& Technology, China 2012.

[48] Dongxu S. Research on dispatching for wind farm integrated system based on power forecasting. PhD Thesis, Beijing Jiaotong Unniversity, China 2014.

[49] Yuanzhang S, Jun H, Guojie L. Dynamic economic dispatch considering wind power penetration based on wind speed forecasting and stochastic programming. Proceedings of the CSEE 2009; 29(4): 41-7.

[50] Gonggui C, Jinfu C. Environmental economic dynamic dispatch modeling and method for power systems integrating wind farms. Proceedings of the CSEE 2013; 33(10): 27-35.

[51] Kennedy S. Wind power planning: assessing long-term costs and benefits. Energy Policy 2005; 33: 1661-75. http://dx.doi.org/10.1016/j.enpol.2004.02.004

[52] Tiejiang $Y$, et al. Electricity market-oriented optimization of environmental economic dispatching for power grid containing wind power. Power System Technology 2009; 33: 131-5.

[53] Qiaoyan Y, Buliu W, Yuewen J. Analysis for reserved capacity of system with wind power connecting into system. Dianli Yu Diangong 2009; 2:32-5.

[54] Bosch PP. Optimal dynamic dispatch owing to spinning reserve and power rate limits. IEEE Trans on Power Apparatus and Systems 1985; 12: 356-65.

[55] Wei Z, Yu P, Hui S, et al. Dynamic economic dispatch in wind power integrated system. Proceedings of the CSEE 2009; 29(25): 13-8.

[56] Hetzer J, Yu DC. An economic dispatch model incorporating wind power. IEEE Trans on Power Energy Conversion 2008; 11: 467-75.

[57] Guohui X. Study on green generation dispatch mode and model. PhD Thesis, North China Electric Power University, China 2010.

[58] Xiaoqiang N. Wind power forecasting technology and its operation analysis. PhD Thesis, Southwest Jiaotong University, China 2012.

[59] Alexiadis MC, Dokopulos PS, Sahsamanoglu HS. Short-term forecasting of wind speed andrelated electrical power. Solar Energy 1998; 63: 61-8. http://dx.doi.org/10.1016/S0038-092X(98)00032-2

[60] Fourly T, Sadany E, Salama M. Grey predictor for wind power energy conversion systems output prediction. IEEE Trans on Power Systems 2006; 21: 1450-2.

http://dx.doi.org/10.1109/TPWRS.2006.879246

[61] Lei D, Lijie W, Ying $\mathrm{H}$. Wind power capacity forecast based on ARMA model. ACTA Energy Solaris Sinica 2011; 32: 61722.

[62] Bates JM, Granger C. The combination of forecast. Operation Research Quarterly 1969; 20: 451-468. http://dx.doi.org/10.1057/jors.1969.103

[63] Mehmet B, Besir S, Abdulkadir Y. Application of artificial neural networks for the wind speed prediction of target station using reference stations data. Renewable Energy 2007; 32: 2350-60. http://dx.doi.org/10.1016/j.renene.2006.12.001

[64] Sfetsos. A novel approach for the forecasting of mean hourly wind speed time series. Renewable Energy 2002; 27: 16374.

http://dx.doi.org/10.1016/S0960-1481(01)00193-8

[65] Damousis IG, Aleciadis MC, Theocharis JB, et al. A fuzzy model for wind speed prediction and power generation in 
wind parks using spatial correlarion. Energy Conversion 2004; 19: 352-61.

http://dx.doi.org/10.1109/TEC.2003.821865

[66] Chun L, Gaofeng F, Weisheng W. A combination forecasting model for wind farm output power. Power System Technology 2009; 33:74-9.

[67] Mohammad M, Rastegar H, Kojabadi HM. A new strategy for wind seed forecasting using artificial intelligent methods. Renewable Energy 2009; 34:845-8.

http://dx.doi.org/10.1016/j.renene.2008.04.017
[68] Folea M, Leahy PG, Marvuflia A, et al. Current methods and advances in forecasting of wind power generation. Renewable Energy 2012; 37:1-8. http://dx.doi.org/10.1016/j.renene.2011.05.033

[69] Jun L. Status and tend analysis on grid integration key technologies of renewable energy power generation. Shanxi Electric 2013; 04: 47-52.

[70] Peng L, Yongrui S, Wei L, et al. Overview and prospect of wind turbine control technologies. Electric Automation 2010; 05: 1-4+7.

Received on 19-12-2014

Accepted on 24-12-2014

Published on 11-03-2015

DOI: http://dx.doi.org/10.6000/1929-6002.2015.04.01.4 